\title{
Diabetes Prevention in Nepal: Assessment of Knowledge and Attitude of the 40+ Patients
}

\author{
Saraswati Sharma ${ }^{1}$ \\ ${ }^{1}$ Ph.D Scholar, Mewar University Gangrar, Chittorgahr Rajasthan India \\ sharmasaraswati505@yahoo.com
}

\begin{abstract}
Introduction: Diabetes was once thought to be a problem exclusively of developed countries and the wealthy. Now diabetes has imposed a heavy burden on both the developed and developing countries. Urbanization, with the adoption of "western lifestyles", has been identified as the main reason. The objective of this study is to explore demographic details of diabetes patients and assess the knowledge and attitude regarding preventive measures on diabetes mellitus among the people above 40 years old in Nepal. Method: Descriptive crosssectional study involving 100 people measure was used to carry out this research. Result: About 20.54\% of the respondents responded that sedentary life style is the main cause of diabetes, $18.98 \%$ pointed out frequent urination as the major symptom. $84 \%$ responded that diabetes could be prevented. $19.04 \%$ considered diet control could help in the treatment of diabetes. $100 \%$ respondent responded that smoking and drinking alcohol should be avoided while $18.98 \%$ took kidney disease and eye problem as the major complications of diabetes. Majority of the respondents ( $88 \%$ ) responded that exercise could help in the control and prevention of diabetes. Conclusion: The risk of diabetes continued to increase worldwide due to population growth, aging, urbanization and increasing prevalence of physical inactivity and obesity. Most of the studies have proved that the number will increase more in developing countries due to rapid urbanization, dietary pattern and sedentary life.
\end{abstract}

\section{KEYWORS}

Attitude, diabetes mellitus, knowledge, practices, prevention.

\section{INTRODUCTION}

Diabetes is a chronic disease that arises when the pancreas does not produce enough insulin, or when the body cannot effectively use the insulin it produces. Failure to produce insulin, or of insulin to act properly, or both, leads to raised glucose (sugar) levels in the blood (hyperglycemia). Globally, rates of type 2 diabetes were 151 million in 2000; the number of people with diabetes worldwide is projected to increase to 366 million by 2030. It is estimated that 20 percent of the current global diabetic population resides in South East Asia region. Type 2 diabetes is the commonest form of diabetes globally as well as in India. It constitutes more than $95 \%$ of the type 2 diabetic populations in India as well as our country. The number of people with diabetes in India, currently around 40.9 million is expected to rise to 69.9 million by 2025, unless urgent preventive steps are taken. (Gujrati, 2013).

As India ranks first in diabetes now and will continue to do so by 2025 , India must prevent the disease by various measures. Before setting the programme, we should have ample data on the population's knowledge, attitude and practice (KAP) of diabetes. (Shah, 2009, July- August). Diabetes has become a significant public health problem in urban Nepal. Studies carried out by the Nepal Diabetes Association in towns and cities throughout the country have revealed a diabetes prevalence of around $15 \%$ among people aged 20 years and above, and 19\% among people aged 40 years and above. The Association has identified a number of key issues which continue to exacerbate this epidemic in Nepal.

A study done on the demographic details of diabetes patients and their knowledge, attitude and practices (KAP) regarding diabetes in Nepal. The KAP scores of the patients were low. This suggests 
the need for educational interventions to improve the knowledge, attitude and practices of the diabetes patients. (Upadhya, 2008).

A study was done to validate knowledge, attitude, and practice (KAP). Questionnaire was administered to both test and control group patients at baseline and at final follow-up to assess awareness regarding disease management. Glucose and lipid levels were also evaluated at baseline and the final follow-up in both the groups. At the end of the study, the KAP score of test group patients improved significantly $(\mathrm{P}<0.0001)$, whereas no significant changes were observed in control group patients. The postprandial blood glucose (PPBG) levels decreased significantly in the test group (Malathy, 2011)

Along with the increase in the incidence of diabetes, both individual and societal expectations concerning the management of diabetes have also increased, with many reports from The Centers for Disease Control (CDC), United States Department of Health and Human Reliable statistics regarding the prevalence of diabetes and its determinants are generally not available from Nepal.

This research study is an attempt to explore and assess the knowledge and attitude regarding preventive measures on diabetes mellitus among the people over 40 years from ward No 1, Pragati Nagar, targeting the people above age group 40 taking 100 sample from the same ward including both male and females. The result explicitly shows that among the various preventive measures to control the diabetes mellitus, the most effective measures are family cooperation, self-awareness and weight control are the three major independent variables.

\section{OBJECTIVE}

The main objective of this study is to assess the knowledge and attitude regarding preventive measures of diabetes mellitus among the people over 40years both male and female of Nepal.

\section{METHODS}

Initially a descriptive measure was used to explore in this research to find out the knowledge and attitude regarding preventive measures among the people over 40 years. In the meantime, a quantitative technique of multiple regression analysis was also used to assess the knowledge of DM and its preventive measures as dependent variables with six sets of independent variables so as to pointed out which one of these independent variables were more significant and crucial to help the patient to prevent DM. The study was carried out in ward no.1 Pragati Nagar, Nawal Parasi for the people over 40 years of age in 100 respondents, with non-probability purposive sampling technique from 2070/6/27-2070/7/20. The researcher collected information conveniently from the respondents by interview with structured and semi-structured questionnaire.

To maintain validity, the instruments were prepared under the guidelines of research supervisor and related literature was reviewed for validity. For reliability $10 \%$ of total population was taken and pretesting was done. Instrument tool was modified as needed after the pre-testing. Level of significance was taken as 5 percent.

A formal permission was obtained from ward No.1, Pragatinagar for data collection in the community. Data were collected by the investigator herself. Interview was taken by using semistructured questionnaire. The collected data were analyzed in SPSS 16.0 version method. Descriptive study was used as mean and standard deviation whereas inferential statistics was used to test the hypothesis for the significance of independent variables. 
Knowledge and attitude regarding preventive measures for diabetes mellitus is taken as major dependent variable and is denoted by script $\mathrm{Y}$. The following six sets of independent variables are taken to assess the DM and multiple regression analysis is employed to assess which one of the following variables are more prominent for the control of DM: Diet Pattern, Control Weight, Family Cooperation, Self-Awareness, Regular Exercise, Lifestyle. These are denoted as X.

\section{RESULTS}

Frequency and percentages are calculated and interpreted through the help of tables and figures to make the data clearer and more meaningful.

Socio Demographic Characteristics: Majority of the respondents were from the age group of 40-50. All of the respondents belonged to the Brahmin/Chhetri caste. Majority of the respondents who were literate, married and residing in joint family.

Knowledge of Diabetes: Eighty six percent of respondents responded that they knew about diabetes whereas only $14 \%$ responded that they had no knowledge about diabetes.

Causes of Diabetes: About 20\% of the respondents responded that sedentary life style was the main cause of diabetes and $14.38 \%$ responded that high intake of rice was the cause of diabetes.

Sign and Symptoms of Diabetes: $18.98 \%$ respondent responded that frequent urination is the main symptoms of diabetes.

Preventive Measures: $84 \%$ responded that diabetes can be prevented.

Treatment Pattern: 19\% responded that diabetes can be controlled by modifying dietary patron Complication: Majority of the respondents responded that kidney and eye problems are the major complications of diabetes.

Blood Sugar Examination: Most of the respondent responded that blood sugar level should be checked regularly however $18 \%$ respondents responded that they don't know about the interval of blood sugar examination.

Types of Food: Most of the respondents responded that fruits can be taken by diabetic patient.

Smoking and Drinking: $100 \%$ of the respondents responded that smoking and drinking should be avoided by diabetic patients.

Diet Schedule: $74 \%$ responded that diabetic patient should take the food in small amount but frequently in a day.

Diet: $32 \%$ responded that rice contain higher carbohydrates than other staple foods.

Exercise: $88 \%$ responded that exercise can help in the control and prevention of diabetes.

Source of Information: 25\% responded that they got the information about diabetes from friends, relatives and family members where as $20 \%$ got the information from television, $19 \%$ from radio as well as newspaper and $16 \%$ from course book.

Attitude Regarding Diabetes: 34\% of respondents reported that diabetes is preventable. $12 \%$ of the respondents responded that diabetes is not curable whereas $24 \%$ respondents reported that diabetes is more common among people over 40 years. 
Attitude Regarding Exercise/Lifestyle/Diet: 40\% respondent totally agreed that the diet regulation can prevent diabetes. Weight control prevents diabetes and people having sedentary lifestyle are more prone to diabetes. $38 \%$ respondents reported that regular exercise can prevent

\section{Regression Analysis}

Table 1: Output of Multiple Regression Analysis

\begin{tabular}{|l|l|l|l|l|l|l|}
\hline $\begin{array}{l}\text { Regression } \\
\text { Statistics }\end{array}$ & & & Coefficients & $\begin{array}{l}\text { Standard } \\
\text { Error }\end{array}$ & t Stat & P-value \\
\hline Multiple R & 0.373683 & Intercept & 10.1573 & 1.941601 & 5.231406317 & $1.03 \mathrm{E}-06$ \\
\hline R Square & 0.139639 & Diet & -0.38869 & 0.225623 & -1.722727279 & 0.088262 \\
\hline Adjusted R Square & 0.084132 & Control weight & -0.81622 & 0.266608 & -3.061486811 & 0.002879 \\
\hline Standard Error & 0.675956 & Family Cooperation & 2.810117 & 0.982828 & 2.85921484 & 0.005242 \\
\hline Observations & 100 & Self -awareness & -2.95928 & 1.031045 & -2.870172396 & 0.005079 \\
\hline & & Regular Exercise & -0.15153 & 0.122166 & -1.240357666 & 0.217963 \\
\hline & & Luxurious Life & 0.176691 & 0.100946 & 1.750340109 & 0.083358 \\
\hline
\end{tabular}

Field Survey: 2013

The analysis is done taking knowledge and attitude regarding preventive measures for diabetes mellitus as dependent variable $(\mathrm{Y})$ with Diet Pattern $\left(\mathrm{X}_{1}\right)$, Control weight $\left(\mathrm{X}_{2}\right)$, Family Cooperation $\left(\mathrm{X}_{3}\right)$, Self-Awareness $\left(\mathrm{X}_{4}\right)$, Regular Exercise $\left(\mathrm{X}_{5}\right)$ and Lifestyle $\left(\mathrm{X}_{6}\right)$ as six sets of independent variables. The output table which comprises of coefficient of determination $\left(\mathrm{R}^{2}\right)$ tries to explain the degree of dependence of dependent variables over the selected independent variables. The value of 0.1396 shows that nearly 14 percent of preventive measures of potential customers' willingness is explained by the six sets of independent variables, which means that besides these variables there are still other variables that can explain the preventive measures of DM.

The data of regression coefficient clearly show the three variables viz family cooperation, self-awareness and weight-control are very prominent variables as their $\mathrm{p}$ values are less than 5\% level of significance, indicating the fact there is a significant relationship between preventive measures of DM and these variables. The data further shows that if family cooperation for the diabetes patient can be fully materialized the possibility of fighting against diabetes increased by $281 \%$. Similarly, developing self-Awareness about diabetes and its consequences will ultimately increase controlling the diabetes by $295 \%$. More precisely, if patient provide sufficient concentration on controlling the weight, than there is the possibility of controlling the diabetes by $82 \%$. In the meantime, other two independent variables viz luxurious life and dietary pattern of the patient show that they are also significant at $10 \%$ level. The regression coefficient shows that $38 \%$ of diabetes problem can be solved if the patient focuses on the dietary pattern whereas eschewing of sedentary life will contribute to $17 \%$ control.

Table 2: ANOVA

\begin{tabular}{|l|l|l|l|l|l|}
\hline & $\begin{array}{l}\text { Degree of } \\
\text { freedom }\end{array}$ & Sum of Square & $\begin{array}{l}\text { Mean Sum of } \\
\text { Square }\end{array}$ & F value & Sig. \\
\hline Regression & 6 & 6.896782217 & 1.149464 & 2.515699 & 0.026635335 \\
\hline Residual & 93 & 42.49321778 & 0.456916 & & \\
\hline Total & 99 & 49.39 & & & \\
\hline
\end{tabular}

Field Survey: 2013

Moreover, the inference about the regression as a whole can be tested using $\mathrm{F}$ value which tests the goodness of fit. The value explicitly shows that multiple regression model is an appropriate 
tool for this analysis and the one of the independent variables has significant relationship with the dependent variables.

\section{DISCUSSION}

Non-communicable disease is scoring over the communicable diseases. Diabetes is an iceberg disease. The increase in both the prevalence and incidence of type 2 diabetes has occurred globally. This study has been conducted about knowledge and attitude regarding preventive measures among the people over 40 years at Pragatinagar in Nawal Parasi. In this study, $70 \%$ respondents are male and $30 \%$ are females.48\% of the respondents are in the age group of 40-50 years. Majority of the respondents are Brahmin/Chhetri i.e 70\%. 100\% of the respondents are Hindus. 80\% respondents are from joint family and $40 \%$ of them are literate who can read and write. $34 \%$ of the respondents had occupation as supernatural healers, retired, astrologers, etc.

In the present study, $86 \%$ responded that they knew about diabetes whereas only $14 \%$ responded that they did know about diabetes. This finding contradicts with the study done by Muninaryan (2010), who has reported that half of the interviewed population have some awareness about diabetes and its symptoms. But more than half (15\%) of them are not aware of the long term effects of diabetes and diabetic care.

About $20.54 \%$ of the respondents responded that sedentary life style is the main cause of diabetes and lowest $14.38 \%$ responded that high intake of rice is the cause of diabetes. This finding is supported by Boulton, W. (2002), who asserts that type 2 DM is usually cause by sedentary lifestyle that leads to obesity and then peripheral insulin resistance.

The present study's findings show that frequent urination is the main symptom of diabetes. But this finding goes counter to the finding of Nisar, N. et al. (2008) who have pointed out that knowledge regarding cause, sign and symptom was found lacking.

Most of the respondents (84\%) responded that diabetes can be prevented. Among them, $19.04 \%$ responded that diabetes can be treated by diet control which is consistent with the study done by Chhetri, \& Chapman (2007).

Majority of the respondents believed that kidney and eye problems are the major complications of diabetes a belief which is at odds with the study done by Muninaryan (2010), who has pointed out that half of the interviewed population had some awareness about diabetes and its complications. However, more than half (15\%) of them in my study were not aware of the long term effects of diabetes.

\section{Knowledge Regarding Preventive Measures}

Most of the respondents responded that blood sugar level should be checked as a wish and 9\% respondents responded that they don't know about the interval of blood sugar examination.

Regarding the knowledge of types of diabetic diet, $25 \%$ reported as cereals, $2.871 \%$ legumes, $2.16 \%$ fruits and $23.95 \%$ milk and milk products. Most of the respondents considered that diabetic patient should take the food in small amount but frequently in a day. The majority of the respondents responded that rice contains high carbohydrates. This study shows that respondents has fairly good knowledge about diabetic diet..

Similar study done by researcher correlates with the present study and KAP scores were satisfactory among our participants. Interestingly $\mathrm{HbAlc}$ and fasting blood glucose levels were far 
from the satisfactory range. The control of DM was also significantly poor $(\mathrm{P}<0.001)$ in $86 \%$ of our study population, irrespective of satisfactory KAP scores ( $\mathrm{Ng}, 2012)$.

At the same time, similar study done by researcher the result does not correlate with this study in so far as the level of knowledge of diabetes is concerned. The study indicates there exist very poor attitudes and practices of the community towards diabetes. A comprehensive nationwide diabetes education programme is necessary to improve this situation. (Kiberenge, 2010, October 6).

Majority of the respondents $88 \%$ responded that exercise can help in the control and prevention of diabetes which reveals that the people have good knowledge about the importance of exercise.

The present study shows that most of the people had correct knowledge regarding diabetic diet and exercise a finding which is consistent with the result of a study conducted about knowledge, attitude and practices regarding Diabetes Mellitus among the community people by (Shrestha, \& Nagra. (2005).

\section{Attitude Regarding Preventive Measures in Diabetes Mellitus}

The most common attitude regarding diabetes is that the disease is preventable. It was reported by $34 \%$ of respondents. $12 \%$ of the respondents responded that diabetes is not curable while $24 \%$ of the respondents reported that diabetes is more common among people over 40 years. The most common attitude regarding exercise, lifestyle and diet was supported by $20(40 \%)$ respondents, who totally agreed that the diet regulation can prevent diabetes. That weight control prevents diabetes and people having sedentary lifestyle invites and exacerbates the disease was equally supported by 16 (32\%) of the respondents. "Patient is responsible for control of diabetes" this statement was totally agreed by maximum i.e. 22 (44\%) of the total respondents. The mean score of attitude among the respondents was found $53.06 \pm 7.43$. As the score is greater than average i.e. 34 ; the attitude of community people is positive, which is consistent with the result of a study conducted aboout knowledge, attitude and practices regarding diabetes mellitus among the people by Shrestha \& Nagra, (2005).

\section{CONCLUSION}

Knowledge is the greatest weapon in the fight against diabetes mellitus. Information can help people assess the risk of diabetes, motivate them to seek proper treatment and care, and inspire them to take charge of their disease. It is, therefore, in the interest of the country to design and develop a comprehensive health promotion strategy for diabetes mellitus and its related risk factors. It is equally important to design and implement suitable diagnostic, management and treatment protocols for people with diabetes. And developing country like Nepal is currently facing the double burden of disease via both communicable and non-communicable diseases. It is imperative that both the government and the community people themselves take necessary steps urgently so that the situation of health crisis may be avoided.

\section{ACKOWLEDGEMENT}

I would like to extend my gratitude to my supervisor Professor Dr. Sarala Joshi for her continuous support and guidance. Also I would like to thank Mr. Krishna Nakarmi for his valuable support for statistical analysis. I would like to express my sincere thanks to the $\mathrm{PhD}$ Centre for providing greater forum to publish the articles. My special thanks go to staffs of the PhD Centre for their support and guidance. I am also thankful to all the participants of my study. 


\section{REFERECNES}

Al-Maskari, F.,EI- Sadig,M.,AI-Kaabi,J.,Afandi,B.,Nagelkerke,N.,\&Yeatts K.B. (2013, January 14). Knowledge, Attitude, and Practices of Diabetic patients in the United Arab Emirates. PLOS, 10021006.

Baddrudin, N., Basti,A., Hydride, M.Z.I \& Hkeem, R. C. (2008). Knowledge, Attitude and Practices of Patient Visiting a Diabetes Care Unit . Retrieved october 4, 2008, from www.pibs.org.

Bazata, D.D., Robinson, J.G., Fox, K.M. and Grandy, S. (2008). Affecting Behaviour change in individule with diabetes. Retrieved October 4, 2012, from Diabetes Education: www.pubmed.com.

Bhandari,D.,\& Shrestha,I. (2004). Prevalance of Diabetes and Profile of Diabetes patient in Nepal. Medical Journal of Nepal , 7-12.

Chhetri, M.R., Chapman, R.S.(2009). Prevalance and Determinants of diabetes among the Elderly Population in the Kathmandu Valley of Nepal. Nepal Medical college Journal;34-38.

Farzana Saleh, Shirin Jahan Saleh,F.,Mumu,S.J., Ara, F., Ali,L., Hossain,S.\& Ahmed,K.R. (2013). Exploring Knowledge, Attitude and practice related to Diabetes in Mongolia:a national population based Survey. BMC Public Health , 13 (236).

Gujrati,A., Sharma,B., \& Jogdand,M. (2013). Assessment of Knowledge, Attitude, Practice,and risk Factors and Associated co-Morbidities in Diabetes Patients. Intenational Journa of medical and Pharmaceutical Sciences , 3 (10), 23-30.

He ,X. \& Wharrad H .J. (2007). Diabetes Knowledge and Glycemic control among Chinese people with typeII diabetes. Pub.Med.NCBI , 54 (3), 280-287.

Katulanda,P., $\quad$ Constantine,G.R., Weerakkody,G., $\quad$ Perera,Y.S.,Jayawardana,M.G.,\& Wijegoponawardena,P. (2011). Can We Brige the gap?Knowledge and Practices related to Diabetes mellitus amonge general practioners in a developing country:A Crosssectional studyAsia Pacific Family Medicine. Asia Pacific Family Medicine , 10 (5), 10-15.

Kheira N., Greerb,W., Yousifa,w.,Geeda,H.A.\& Okkahaa,R.A. (2011, March 8). Knowledge, Attitude, and Practice of Qatari patient with Type II diabetes. Mellitiu. IJPP .

Ng, S. H., Chan, K.H.,Lian,Z.Y., Chuah, Y.H.,Waseem, A.N.\& Kadirvelu,A. (2012). Reality Versus Illusion:Knowledge, Attitude, and practice amonge diabetes patient. International Journal of collabourative Research on Internal medicine and Publice Health , 4 (5), 102-106.

Shah, V. N., Kamdar, P. K.\& Shah,N. (2009). Assessing knowledge,Attitude and practice of type II diabetes among patient of saurastra region, Gujarat. International Journal of Diabetes in developing countries, 29, 118-122.

Shera,A.S. \& Jawad, A. (2002). Diabetes related Knowledge, Attitude and Practice of family Physician in Pakistan. JPMA, 52 (465).

Upadhaya,D.K.Palaian,S.\& Ravi shanker,P. (2008). Knowledge, Attitude, and Practice about Diabetes among diabetes patient. RMJ, 33 (1), 8-11. 